\title{
Middle Jurassic cyclostome bryozoans from the Polish Jura
}

\author{
Michał Zatoń and Paul D. Taylor \\ Acta Palaeontologica Polonica 54 (2), 2009: 267-288 doi:http://dx.doi.org/10.4202/app.2008.0088
}

New collections of bryozoans from the Middle Jurassic (Late Bajocian and Bathonian) of Poland add significantly to our

knowledge of the diversity and biogeography of the Cyclostomata at a time when they were the dominant bryozoan order in the fossil record. A total of 16 species and one form-genus ("Berenicea") are present. Most are encrusters, predominantly on hiatus concretions. A single erect species was found in deposits interpreted as regurgitates of a marine vertebrate.

The following new species are described: Microeciella annae sp. nov., M. kuklinskii sp. nov., M. maleckii sp. nov., M. mokrskoensis sp. nov., M. magnopora sp. nov., Reptomultisparsa harae sp.

nov., and Hyporosopora bugajensis sp. nov. The taxonomic importance of the morphology of both the gonozooids and pseudopores is underlined, especially for encrusting species of the "Berenicea" type that are otherwise difficult to distinguish from one another. The described bryozoan assemblage encrusting hiatus concretions from the Polish Middle Jurassic is the richest that has been documented globally from this kind of substrate.

Key words: Bryozoa, Cyclostomata, Middle Jurassic, Bajocian, Bathonian, Poland.

Michał Zatoń [mzaton@wnoz.us.edu.pl], University of Silesia, Faculty of Earth Sciences, Będzińska 60, 41-200 Sosnowiec, Poland; Paul D. Taylor [p.taylor@nhm.ac.uk], Natural History Museum, Department of Palaeontology, Cromwell Road, London SW7 5BD, United Kingdom.

This is an open-access article distributed under the terms of the Creative Commons Attribution License (for details please see creativecommons.org), which permits unrestricted use, distribution, and reproduction in any medium, provided the original author and source are credited. 
